\title{
Comparing the Operational Strategies of South Korea and Israel's Coronavirus Drive-Through Testing Centers and the Implications on Testing Capacity
}

This article was published in the following Dove Press journal:

Risk Management and Healthcare Policy

\section{Edward Kim (DD}

Medical School for International Health, Ben Gurion University of the Negev, Beer Sheva, Israel
Correspondence: Edward Kim Medical School for International Health, Ben Gurion University of the Negev, P.O. Box 653, Beer Sheva 841050I, Israel Email contact@eddiewkim.com

\begin{abstract}
There is an increased need for mass testing in the setting of an emerging infectious disease pandemic to foster informed policymaking and improve public health outcomes. Drive-through testing centers have been employed with great success in South Korea and Israel. In highlighting the differences and examining the downstream implications of their logistical and operational strategies, this paper provides valuable insight on areas of improvement that can increase the capacity and efficiency of testing with drive-through testing centers.
\end{abstract}

Keywords: screening, pandemic, COVID-19, nCoV2019, SARS-CoV-2

\section{Introduction}

Shortly after coronavirus disease 2019 (COVID-19) presented in China, the novel coronavirus quickly spread to other countries, including South Korea and Israel. The first reported case of COVID-19 in South Korea was confirmed on January 20 and Israel reported their first case a month later, on February $21 .^{1}$ This lead-time is valuable as countries in earlier stages of addressing the virus have the opportunity to adopt and adapt practices used in other countries further along in the process. As the virus continues to spread, there is an urgent need to increase availability, capacity, and efficiency of testing, which in turn allows for informed policy decisions, better utilization of limited resources, and more effective containment of the virus. ${ }^{2,3}$

While the need for testing continues to grow, decisions must be made on how to best expand disease surveillance in different settings with limited healthcare resources. In response, several countries have initiated drive-through testing centers. Examining their operational differences as well as subsequent advantages and disadvantages provide valuable insight to other countries that are in the process of designing and implementing drive-through testing centers - enabling them to develop their testing capacity and improve public health outcomes.

\section{Overview of Drive-Through Testing Centers}

Drive-through testing centers have been implemented in China, South Korea, Israel, and the United States as a safer and more efficient alternative to testing within 
a clinic or hospital setting. Previously, the drive-through model was studied as a strategy in response to a bioterrorism attack and for dispensing medications to a high volume of people. ${ }^{4,5}$ However, in the context of preparing for an infectious disease pandemic, this approach was validated and tested for feasibility predominately in a theoretical and controlled setting. ${ }^{6}$

In response to COVID-19, drive-through testing centers are generally set up such that individuals arrive at the site in their vehicle and drive up to various stations that include registration, examination, specimen collection, and discharge instructions. To limit the potential of cross-contamination, those who are tested remain in their vehicle at all times.

Accordingly, the vehicle serves as a mobile examination room. This not only reduces the risk of infection associated with being in a crowded waiting room but also overcomes delays associated with cleaning and turning over a traditional exam room. ${ }^{7}$ More broadly, this testing method relieves over-extended hospital facilities and allows health systems to increase their capacity to address more urgent and acute care needs, which has been shown to improve clinical outcomes. ${ }^{8}$

Despite its advantages, drive-through testing is only accessible to individuals with access to private transportation. Another drawback is if a health emergency arises and the testing facility is not located close to a hospital, patients do not have access to immediate medical care. Israel has addressed these gaps by providing home visits and equipping their drive-through centers with emergency medical services. ${ }^{9}$

\section{Comparing South Korea and Israel's Approaches}

While there are many similarities between South Korea and Israel's drive-through testing centers, there are significant differences that stem from their core focus and operational directives. While both countries share the goal of scaling testing capacity, South Korea focused more on expanding the number of facilities throughout the country, while Israel concentrated on maximizing efficiency of each testing center.

In terms of process, both countries began by piloting a single testing center and then quickly operationalized multiple testing sites. South Korea started with a facility at Chilgok Kyungpook National University Medical Center in Daegu, where the initial outbreak occurred. ${ }^{10}$ Israel began by their efforts in Tel Aviv, the most densely populated city in the country. ${ }^{11}$ However, the countries' strategy departed in terms of the distribution and number of testing centers. Whereas South Korea set up over 65 centers, Israel operated less than 15 and concentrated on major metropolitan cities. ${ }^{10}$ Despite the significantly lower number of facilities, Israel was able to still increase its testing capacity by having each testing center accommodate up to 6 cars in parallel, while the South Korean testing center can typically test up to 2 simultaneously. ${ }^{12}$ All else being equal, this would allow up to a three-fold increase in patients tested per testing center.

Another important factor is throughput, which is defined as the number of individuals or cars that can be tested within a certain timeframe per vehicle lane. South Korea reports processing, on average, a car every 10 minutes while Israel reports one every 3-5 minutes. Israel was able to achieve a two-fold increase in throughput by providing only the most essential services, collecting patient information in advance of their arrival at the facility, and screening patients over the phone to assess their likelihood of contracting the virus prior to authorizing testing. ${ }^{12}$

South Korea's drive-through testing center required additional administrative steps at the beginning of testing to collect personal information, epidemiologic factors, symptoms, and payment for services. Moreover, in addition to performing nasopharyngeal swabs, medical volunteers took samples of saliva and used contactless thermometers to take temperature. ${ }^{10}$ Alternatively, Israel leveraged their increased call center capacity - which is run by Magen David Adom, the country's national emergency pre-hospital medical and blood services organization. ${ }^{13}$ This enabled Israel to collect pertinent information prior to on-site testing, screen for COVID-19 symptoms, assess the individual likelihood of contracting the virus, and schedule patients to reduce wait times. Scheduling also avoided the issue of individuals visiting multiple testing centers - an issue that South Korea was unable to systematically avoid and that resulted in repeated tests and the misuse of resources. ${ }^{10}$

\section{Discussion}

Israel had an advantage of a 1-month delay over South Korea in active COVID-19 cases. This provided the country with additional leeway to refine their drive-through testing center model and roll-out of facilities. Although the countries' drive-through testing centers are similar in many respects, they prioritized expanding testing capacity differently; namely, distribution in South Korea and efficiency in Israel. Both of their models and facilities were 
well designed and led to improved testing capacity. Nevertheless, highlighting the operational differences and comparing the resulting throughput metrics provide valuable insight on areas of improvement that can enhance mass testing and efficiency in other countries.

It is evident that differences in operational directives and seemingly minor changes in processes can lead to significant improvements in throughput. If these strategies are implemented at a national level, they can lead to major differences in testing capacity and subsequently containment of disease. However, further study that examines the other aspects of the testing continuum such as time from suspicion of virus exposure to testing and proportion of the population tested is required. Having the ability to identify areas of improvement in COVID-19 testing carries significant public health implications and help guide policy decisions for countries that are beginning to, or are currently operating, drive-through testing centers.

\section{Disclosure}

The author has no potential conflicts of interest to disclose.

\section{References}

1. World Health Organization. Situation report - 33; 2020:7. Available from: https://www.who.int/docs/default-source/coronaviruse/situationreports/20200222-sitrep-33-covid-19.pdf?sfvrsn=c9585c8f_4. Accessed March 25, 2020.

2. Li R, Pei S, Chen B, et al. Substantial undocumented infection facilitates the rapid dissemination of novel coronavirus (SARS-CoV2). Science. 2020;10:eabb3221. doi:10.1126/science.abb3221
3. Walensky RP, Del Rio C. From mitigation to containment of the COVID-19 pandemic: putting the SARS-CoV-2 genie back in the bottle. JAMA. 2020;323(19):1889. doi:10.1001/jama.2020.6572

4. Baccam P, Willauer D, Krometis J, Ma Y, Sen A, Boechler M. Mass prophylaxis dispensing concerns: traffic and public access to PODs. Biosecur Bioterror. 2011;9(2):14.

5. Zerwekh T, McKnight J, Hupert N, Wattson D, Hendrickson L, Lane D. Mass medication modeling in response to public health emergencies: outcomes of a drive-thru exercise. J Public Health Manag Pract. 2007;13(1):7-15. doi:10.1097/00124784-20070100000003

6. Weiss EA, Ngo J, Gilbert GH, Quinn JV. Drive-through medicine: a novel proposal for rapid evaluation of patients during an influenza pandemic. Ann Emerg Med. 2010;55(3):268-273. doi:10.1016/j. annemergmed.2009.11.025

7. Goodman RA, Solomon SL. Transmission of infectious diseases in outpatient health care settings. JAMA. 1991;265(18):2377-2381. doi:10.1001/jama.1991.03460180083038

8. Bernstein SL, Aronsky D, Duseja R, et al. The effect of emergency department crowding on clinically oriented outcomes. Acad Emerg Med. 2009;16(1):1-10. doi:10.1111/j.1553-2712.2008.00295.x

9. Adom MD. Drive and check; March 22, 2020. Available from: https://www.mdais.org/en/news/210320. Accessed March 25, 2020.

10. Kwon KT, Ko J-H, Shin H, Sung M, Kim JY. Drive-through screening center for COVID-19: a safe and efficient screening system against massive community outbreak. J Korean Med Sci. 2020;35 (11):e123. doi:10.3346/jkms.2020.35.e123

11. Statistical Abstract of Israel 2019. Central Bureau of Statistics; 2019. Available from: https://www.cbs.gov.il/en/publications/Pages/2019/ Statistical-Abstract-of-Israel-2019-No-70.aspx. Accessed March 25, 2020.

12. Kim E. Drawing on Israel's experience organizing volunteers to operationalize drive-through coronavirus testing centers. Disaster Med Public Health Prep. 2020;1-7. doi:10.1017/dmp.2020.104

13. Adom MD. The Joint Hotline of the Ministry of Health, Health Insurance Companies and Magen David Adom Opens; February 22, 2020. Available from: https://www.mdais.org/en/news/2202201. Accessed March 25, 2020.
Risk Management and Healthcare Policy

\section{Publish your work in this journal}

Risk Management and Healthcare Policy is an international, peerreviewed, open access journal focusing on all aspects of public health, policy, and preventative measures to promote good health and improve morbidity and mortality in the population. The journal welcomes submitted papers covering original research, basic science, clinical \& epidemiological studies, reviews and evaluations, guidelines, expert opinion and commentary, case reports and extended reports. The manuscript management system is completely online and includes a very quick and fair peer-review system, which is all easy to use. Visit http://www.dovepress.com/testimonials.php to read real quotes from published authors. 